\title{
User requirements for image-guided navigation in spinal surgery
}

\author{
M. P. Craven, L. Pecchia and J. L. Martin \\ University of Nottingham, Faculty of Engineering, Division of Electrical Systems and Optics, Nottingham, United Kingdom
}

\begin{abstract}
Advances in image-guided technology have resulted in a number of technologies to support surgeons in the identification of tissue and the tracking and navigation of surgical instruments in spinal surgery. There are various existing and proposed systems to support registration and intraoperative image guidance based on fluoroscopy, Computerized Tomography (CT), Magnetic Resonance Imaging (MRI) and ultrasound (US) or combinations of imaging modalities. However, the user requirements for the design of such systems are complex, dependent on medical specialty in addition to the range of instrumented and non-instrumented treatments offered in the orthopedic and neurological domains. This paper presents a review and study of user requirements for intraoperative navigation in spinal surgery. The numerous outcomes measures for successful operations are outlined, that provide a basis for understanding the needs of surgeons. A hierarchy of needs is then presented that can be used to inform an Analytic Hierarchy Process for elicitation of detailed user requirements.
\end{abstract}

Keywords - Imaging, Navigation, Spinal surgery, Health Technology Assessment, User requirements

\section{INTRODUCTION}

Significant advances in imaging and tracking technologies have enabled the field of computer-assisted or imageguided spinal surgery to progress in recent years and the aim of minimally invasive spinal surgery is being realized [1]. However, spinal surgery is a complex area to support from a technology point of view, with more than one surgical specialty to consider including orthopedics where it may be necessary to identify and fix bone e.g. to resect vertebrae or insert pedical screws to fix spinal support instruments [2] or in neurosurgery to remove tumors [3-6]. Spinal surgery also has implications for the vascular system.

The process of navigation involves capture of preoperative images, which are typically obtained from a preoperative scan. The pre-operative images must then be registered with images captured during surgery in order to support navigation of instruments and surgical intervention based on dynamic information.

The range of available imaging modalities such as fluoroscopy, Computerized Tomography (CT), Magnetic Resonance Imaging (MRI) and ultrasound (US) vary in their ability to support the range of possible surgical interventions on different parts of the spine. Elective surgery to correct degeneration on an elderly adult lumbar spine with instruments fixed with pedical screws has different requirements to that of removing a primary tumor on a pediatric thoracic spine, for example. There will be a benefit to avoiding vascular complication in both types of treatment.

Therefore, when designing a navigation system for spinal surgery, it is important to fully understand the criteria for success in terms of the outcomes sought by surgeons. The authors have previously found a complex set of opinions on factors influencing the success of hip and knee surgery [7]. It is clear that system developers must discover precisely what surgeons think are the important influencers on the success of surgery in order to focus development on finding solutions to those needs. This is a general issue in medical device design whereby a structured approach to usability engineering is beneficial to developers of innovative products [8].

For this study we begin with identifying outcomes and then create an initial hierarchy of needs that can be used by developers to inform system design.

\section{REVIEW OF SUCCESS CRITERA}

The study aimed to determine the criteria of success for spinal surgery with regard to three main areas: patientoriented clinical outcomes; technical clinical outcomes; and other issues.

We first consider patient-oriented clinical outcomes measures based on criteria included in British Association of Spine Surgeons (BASS) [9] audits. These are based on three audit topics as used in the 2011 and 2010 audits as follows:

1. Single level, unilateral primary lumbar discectomies age $<=50$

2. Single level, unilateral primary surgical procedure for an L4/5 degenerate spondylolisthesis $>=50$

3. 3 or more level primary lumbar decompressions without instrumentation

Data for the BASS audits was collected to include the following: Mean age of patient; Annual number of procedures; Level(s) operated and number of levels (where relevant); Type of decompression or fusion. Outcomes recorded in the audits included rate of recurrence (early 
revision) and incidence of complications including dural tear, infection, and nerve injury. Pre-operative and postoperative scores were recorded including the Oswestry Disability Index (ODI) and Visual Analogue Score (VAS) for leg pain.

We compared the features of the BASS audit data-set with data and outcomes recorded in two Norwegian studies. Outcomes measures for decompressive laminectomy for lumber spinal stenosis in the elderly [10] included ODI and VAS plus quality of life measures EQ-5D and EQ-VAS, a benefits scale question taken at follow-up (e.g. "How much benefit have you had from the operation?") and walking capability. Length of hospital stay was included in patient characteristics. Complications included: Minor (Dural tear, Superficial wound infection); Major (Perioperative death within 30 days; Upper URI (Respiratory Tract Infection); Deep wound infection; Myocardial infarction (non-fatal); Gastric ulcer. Similar data collection and outcome measures were presented for patients operated on for degenerative spinal disorders [11]; patient characteristics recorded included: Weeks on sick leave; Days of hospital stay; Complication rate; EQ-5D; Health state; Leg pain; Back pain; Anxiety and/or depression. Complications included: Dural tear; Deep wound infection; Superficial wound infection; Urinary bladder infection; Reoperation within the same hospital stay, Intraoperative nerve root injury, Postoperative muscle hernia, Gall bladder infection, Deep leg vein thrombosis, Gastric ulcer hemorrhage, Minor myocardial infarction.

Elsewhere in the literature, for cervical spine, Neck Disability Index (NDI) short form-36 (SF-36) physical component summary, and pain scales for neck and arm pain are of relevance [12], and in addition to ODI, back-specific measures include the Roland-Morris Disability Questionnaire (RDQ) [13].

Mortality and morbidity rates have been outlined for spine surgery in general highlighting a broad range of postoperative outcomes and associated risk factors [14]. For spinal neurosurgery we can also add measures of amount of residual tumor detected [15] and rates of various complications [16]. Other complications not mentioned in the above audits or registry studies are: Vascular injury including blood loss or (rare) iatrogenic thoracic aortic injury cases $[17,18]$; radiation injury [19].

Therefore it can be seen that there are many outcomes measures to consider in spinal surgery, including both clinical and patient-reported measures that are of relevance to the surgeon when assessing the success of surgery, and while some standardization is evident, there are differences in national systems.
We now consider the more technical measures that are related to the surgical goal i.e. the success of the surgical process.

There is a good body of literature for spine surgery concerned with the timing of registration and accuracy of pedicle screw placement that is related to the quality of registration or navigation [2]. Table 1 shows some examples that include mean surgical time, timing of image registration, grading or counting of breaches, perforations, misplacements or deviations of screws and percentage of screws requiring replacing. In addition to timing and accuracy measures, a percentage of pedicle screws may be considered 'non-navigable', requiring the use of another imaging technique or manual placement. Gebhard and Arand found that computer-assisted implantation was not possible in $15 \%$ of cases and cited earlier studies with up to $32 \%$ non-navigable pedicles [20].

Table 1 Outcomes for pedical screw placement

\begin{tabular}{|c|c|c|c|}
\hline $\begin{array}{l}\text { Refer- } \\
\text { ence }\end{array}$ & Surgical goal & $\begin{array}{l}\text { Imaging sys- } \\
\operatorname{tem}(s)\end{array}$ & Measure \\
\hline$[21]$ & $\begin{array}{l}\text { Spinal stabiliza- } \\
\text { tion using pedical } \\
\text { screws. Single, } \\
\text { bilevel and multi- } \\
\text { level up to } 4 \\
\text { levels. }\end{array}$ & $\begin{array}{l}\text { Medtronic O- } \\
\text { arm 2D pre-op } \\
\text { then 3D and } \\
\text { Stealthstation } \\
\text { Treon plus. }\end{array}$ & $\begin{array}{l}\text { Mean surgical } \\
\text { time. Percen- } \\
\text { tage perfora- } \\
\text { tion of pedi- } \\
\text { cal screw. } \\
\text { Percentage } \\
\text { replacement } \\
\text { of screws. }\end{array}$ \\
\hline [22] & $\begin{array}{l}\text { Minimally inva- } \\
\text { sive lumbar fusion } \\
\text { with pedicle screw } \\
\text { fixation. Single } \\
\text { and multilevel. }\end{array}$ & $\begin{array}{l}\text { CT pre-op then } \\
\text { O-arm and } \\
\text { Stealthstation } \\
\text { Treon }\end{array}$ & $\begin{array}{l}\text { Accuracy of } \\
\text { screw place- } \\
\text { ment graded } \\
\text { as millimetre } \\
\text { breaches. } \\
\text { Overall } \\
\text { misplacement } \\
\text { rate. }\end{array}$ \\
\hline [23] & $\begin{array}{l}\text { Whole spine } \\
\text { imaging. Multi- } \\
\text { level. }\end{array}$ & $\begin{array}{l}\text { C-arm fluoros- } \\
\text { copy }\end{array}$ & $\begin{array}{l}\text { Timing of } \\
\text { registration } \\
\text { until start of } \\
\text { navigation. } \\
\end{array}$ \\
\hline [24] & $\begin{array}{l}\text { Instrumented } \\
\text { treatment of } \\
\text { scoliosis using } \\
\text { pedical screws in } \\
\text { idiopathic, symp- } \\
\text { tomatic and } \\
\text { congenital spinal } \\
\text { surgery. }\end{array}$ & $\begin{array}{l}\text { Stealthstation } \\
\text { CT then surface } \\
\text { registration on } \\
\text { to CT. }\end{array}$ & $\begin{array}{l}\text { Screw devia- } \\
\text { tion. Duration } \\
\text { of registra- } \\
\text { tion. }\end{array}$ \\
\hline [25] & $\begin{array}{l}\text { Treatment of } \\
\text { degenerative } \\
\text { disease. } 12 \text { cases. } \\
\text { Cervical and } \\
\text { lumber. Single } \\
\text { and multilevel. } \\
\end{array}$ & $\begin{array}{l}\text { General Electric } \\
\text { inter-opertaive } \\
\text { MRI }\end{array}$ & $\begin{array}{l}\text { Overall } \\
\text { operating } \\
\text { time. }\end{array}$ \\
\hline
\end{tabular}

Difference of opinion is expected amongst neurosurgeons versus orthopedic surgeons as to what constitutes surgical

Craven, M. P., Pecchia, L., Martin, J. L. User requirements for image-guided navigation in spinal surgery, in Long, M. (Ed.), IFMBE Proceedings, Vol 39, World Congress on Medical Physics and Biomedical Engineering, May 26-31 2012, Beijing, China. Springer, Berlin, 2012. 
excellence [26]. Schroder and Wassman [27] point to a range of opinion amongst German neurosurgical departments about navigation technology for insertion of pedical screws ranging from "not useful at all" to "malpractice if not using it". They also found that opinion was divided on the safety benefits of using neuro-navigation for spinal surgery with $49 \%$ responding that it enhances safety whereas $37 \%$ reported that it did not and $14 \%$ were unsure.

For orthopedic surgeons, with reference to knee surgery, computer-assisted surgery (CAOS) promises better accuracy, control and feedback to the surgeon, an ability to correct errors and provision of documentation that are afforded by a computer-assisted system [28]. These benefits have the potential to offset the increased capital cost, requirement for additional imaging modalities, and increased length of surgery [29]. Similarly, the hope for Computer-assisted spinal surgery (CASS) is that it will reduce the overall morbidity of spine surgery with less surgical dissection, reduced hospital stay, early mobilization and early healing [30]. There is evidence that navigation reduces the time for pedicle screw placement in spine surgery. For neurosurgeons, however, 'less dissection' may be better stated as optimal resection for tumor removal since it is a surgical goal to avoid residual tumor.

Fritsch comments in some detail on the benefits and disadvantages of CT versus 'virtual fluoroscopy' [31]. CTbased navigation disadvantages were: calculating power (although this has advanced since 2004); scan protocols for preoperative planning and artefacts; requirement for vertebral bodies to be intact, mathematical tilting of the vertebral body in the CT scan; and movement of the anatomical situation that affects the preoperative dataset. Furthermore CT radiation is a limitation primarily in surgery for scoliosis (see also [30]). Advantages of virtual fluoroscopy are: presence of the fluoroscope during surgery; automatic registration; recent anatomical situation; ability to perform updates at any time. Limitations are: changing of the shape of the fluoroscope radiation cone as its position is changed; distortions; geometrical error due to the reduction of 3D to 2D.

MRI is suited to soft-tissue imaging and has been investigated for use in intra-operative spine surgery. However it is expensive and there are some difficulties in using it during surgery $[25,32,33]$.

Ultrasound imaging also has potential to be used in spinal navigation $[15,34]$. Kolstad et al. outline the problem of $2 \mathrm{D}$ ultrasonography in the positioning of the operating instruments since the orientation of the probe must be taken into account to estimate the depth of the lesion, whereas 3D-US (where an image volume is generated by tilting or translating the probe) is able to locate the probe in 3D space. Image acquisition requires the clamping of a reference frame to the patient, preferably near the tumor to re- duce error, and the surgeon then moves the probe within the region of interest to obtain the 3D image. Following image acquisition, navigation with a pointer device or surgical instrument that is calibrated to the navigation system may proceed without an additional reference (frameless navigation). Kolstad et al. also consider the sources of anatomical shifts in spine surgery that present a challenge for navigation systems.

\section{ANALYTIC HIERARCHY PROCESS DESIGN}

AHP is a multi-dimensional, multi-level and multifactorial decision-making method based on the idea that it is possible to prioritize factors by: grouping them into meaningful categories and sub-categories; performing pairwise comparisons among factors; defining a coherent framework of quantitative and qualitative knowledge, measuring also intangible domains [35].

User requirements issues identified from the literature are used to inform the design of categories for pre-, intra- and post-surgery in order to design an initial example of AHP hierarchy for expert elicitation from surgeons (Fig. 1).

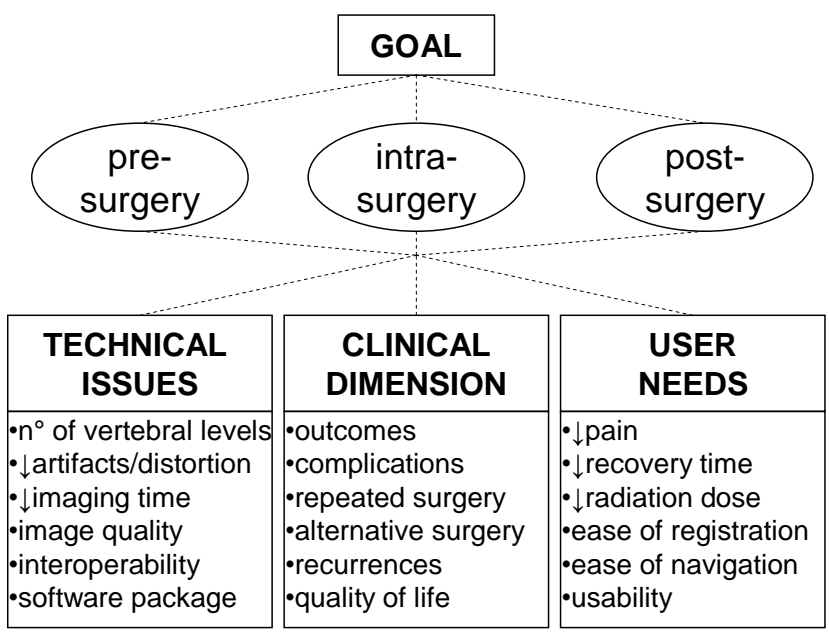

Fig. 1 example of hierarchy for user needs elicitation.

\section{CONCLUSIONS}

This paper has reviewed outcomes measures for spinal surgery that should feed into the development process of technology innovations in image-guided spinal surgery. Criteria for success can be expressed in both clinical and technical terms and depend on surgical specialty. An understanding of these criteria has been used to inform the design of an Analytic Hierarchy Process questionnaire for spinal surgeons. 


\section{ACKNOWLEDGMENT}

The authors acknowledge the collaboration of Tormod Selbekk of SINTEF in Trondheim, Norway, for organizing a meeting where we were able to gain insights into the problems of spinal imaging from the surgeon perspective. The authors acknowledge support of this work through the MATCH Programme (EPSRC Grant EP/F063822/1) although the views expressed are entirely their own.

\section{REFERENCES}

1. Kim, C.W., et al., The current state of minimally invasive spine surgery. J Bone Joint Surg Am, 2011. 93(6): p. 582-96.

2. Tjardes, T., et al., Image-guided spine surgery: state of the art and future directions. Eur Spine J, 2010. 19(1): p. 25-45.

3. Akram, H. and J. Allibone, Spinal surgery for palliation in malignant spinal cord compression. Clin Oncol (R Coll Radiol), 2010. 22(9): $\mathrm{p}$. 792-800.

4. Aghayev, K., F. Vrionis, and M.C. Chamberlain, Adult intradural primary spinal cord tumors. J Natl Compr Canc Netw, 2011. 9(4): p. 434-47.

5. Chamberlain, M.C. and T.L. Tredway, Adult primary intradural spinal cord tumors: a review. Curr Neurol Neurosci Rep, 2011. 11(3): p. 3208.

6. Cloyd, J.M., et al., En bloc resection for primary and metastatic tumors of the spine: a systematic review of the literature. Neurosurgery, 2010. 67(2): p. 435-44; discussion 444-5.

7. Davey, S.M., et al., Surgeon opinion on new technologies in orthopaedic surgery. J Med Eng Technol, 2011. 35(3-4): p. 139-48.

8. Martin, J.L., et al., A user-centred approach to requirements elicitation in medical device development: A case study from an industry perspective. Applied Ergonomics, 2012. 43(1): p. 184-190.

9. BASS. British Association of Spine Surgeons. 2011; Available from: www.spinesurgeons.ac.uk.

10. Jakola, A.S., et al., Clinical outcomes and safety assessment in elderly patients undergoing decompressive laminectomy for lumbar spinal stenosis: a prospective study. BMC Surg, 2010. 10: p. 34.

11. Solberg, T.K., et al., Would loss to follow-up bias the outcome evaluation of patients operated for degenerative disorders of the lumbar spine? Acta Orthop, 2011. 82(1): p. 56-63.

12. Carreon, L.Y., et al., Neck Disability Index, short form-36 physical component summary, and pain scales for neck and arm pain: the minimum clinically important difference and substantial clinical benefit after cervical spine fusion. Spine J, 2010. 10(6): p. 469-74.

13. Bombardier, C., Outcome assessments in the evaluation of treatment of spinal disorders: summary and general recommendations. Spine (Phila Pa 1976), 2000. 25(24): p. 3100-3.

14. Schoenfeld, A.J., et al., Risk factors for immediate postoperative complications and mortality following spine surgery: a study of 3475 patients from the National Surgical Quality Improvement Program. J Bone Joint Surg Am, 2011. 93(17): p. 1577-82.

15. Mercier, L., et al., New prototype neuronavigation system based on preoperative imaging and intraoperative freehand ultrasound: system description and validation. Int J Comput Assist Radiol Surg, 2011. 6(4): p. 507-22.

16. Boriani, S., et al., Morbidity of en bloc resections in the spine. Eur Spine J, 2010. 19(2): p. 231-41.

17. Jim, J., L.A. Sanchez, and P.J. Geraghty, Endovascular repair of an intraoperative thoracic aortic injury during all-posterior vertebral column resection surgery. Ann Vasc Surg, 2011. 25(1): p. 132 e1-6.
18. Minor, M.E., et al., Endovascular treatment of an iatrogenic thoracic aortic injury after spinal instrumentation: case report. J Vasc Surg, 2004. 39(4): p. 893-6.

19. Hoang, J.K., et al., Radiation dose exposure for lumbar spine epidural steroid injections: a comparison of conventional fluoroscopy data and CT fluoroscopy techniques. AJR Am J Roentgenol, 2011. 197(4): p. 778-82.

20. Gebhard, F. and M. Arand, Navigation of Tumor and Metastatic Lesions in the Thoracolombar Spine, in Navigation and robotics in total joint and spine surgery, J.B. Stiehl, W.H. Konermann, and R.G. Haaker, Editors. 2004, Springer: Berlin. p. 495-500.

21. Oertel, M.F., et al., Clinical and methodological precision of spinal navigation assisted by $3 D$ intraoperative $O$-arm radiographic imaging. J Neurosurg Spine, 2011. 14(4): p. 532-6.

22. Park, P., et al., Minimally invasive pedicle screw fixation utilizing $O$ arm fluoroscopy with computer-assisted navigation: Feasibility, technique, and preliminary results. Surg Neurol Int, 2010. 1: p. 44.

23. Nottmeier, E.W. and T. Crosby, Timing of vertebral registration in three-dimensional, fluoroscopy-based, image-guided spinal surgery. J Spinal Disord Tech, 2009. 22(5): p. 358-60.

24. Nakanishi, K., et al., Usefulness of a navigation system in surgery for scoliosis: segmental pedicle screw fixation in the treatment. Arch Orthop Trauma Surg, 2009. 129(9): p. 1211-8.

25. Woodard, E.J., et al., Initial experience with intraoperative magnetic resonance imaging in spine surgery. Spine (Phila Pa 1976), 2001. 26(4): p. 410-7.

26. Sonntag, V.K., Excellence in spinal neurosurgery. Clin Neurosurg, 2010. 57: p. 15-8.

27. Schroder, J. and H. Wassmann, Spinal navigation: an accepted standard of care? Zentralbl Neurochir, 2006. 67(3): p. 123-8.

28. Sikorski, J.M. and S. Chauhan, Computer-assisted orthopaedic surgery: do we need CAOS? J Bone Joint Surg Br, 2003. 85(3): p. 31923 .

29. Dong, H. and M. Buxton, Early assessment of the likely costeffectiveness of a new technology: A Markov model with probabilistic sensitivity analysis of computer-assisted total knee replacement. Int $\mathrm{J}$ Technol Assess Health Care, 2006. 22(2): p. 191-202.

30. Purushothamdas, S. and A.R. Meir, Computer-assisted Spinal Surgery for Deformity - A Review, in European Musculoskeletal Review2011, Touch Briefings: http://www.touchmusculoskeletal.com. p. 48-54

31. Fritsch, E.W., Navigation in Spinal Surgery using Fluoroscopy, in Navigation and robotics in total joint and spine surgery, J.B. Stiehl, W.H. Konermann, and R.G. Haaker, Editors. 2004, Springer: Berlin. p. 487-494.

32. Martel, A.L., et al., Assessment of 3-dimensional magnetic resonance imaging fast low angle shot images for computer assisted spinal surgery. Comput Aided Surg, 1998. 3(1): p. 40-4.

33. Tate, P.M. and M.A. Chapman, The assessment of magnetic imagery for computer assisted spinal surgery. International Archives of Photogrametry and Remote Sensing, 2000. 33: p. 809-816.

34. Kolstad, F., et al., Three-dimensional ultrasonography navigation in spinal cord tumor surgery. Technical note. J Neurosurg Spine, 2006. 5(3): p. 264-70.

35. Liberatore, J.M., Nydick. R.L., The analytic hierarchy process in medical and health care decision making: A literature review, European Journal of Operational Research, 2008, 189(1): 194-207.
Author: Michael P. Craven
Institute: University of Nottingham, Faculty of Engineering, Division of Electrical Systems and Optics
Street: University Park, Tower Building
City: Nottingham
Country: United Kingdom
Email: michael.craven@nottingham.ac.uk

Craven, M. P., Pecchia, L., Martin, J. L. User requirements for image-guided navigation in spinal surgery, in Long, M. (Ed.), IFMBE Proceedings, Vol 39, World Congress on Medical Physics and Biomedical Engineering, May 26-31 2012, Beijing, China. Springer, Berlin, 2012. 